\title{
Hydraulic Couplings and Torque Converters
}

$I^{\mathrm{T}}$ is indicative of the interest being taken by engineers in the comparatively recent hydraulic method of transmitting torque and to the importance attached to its development that three papers on this subject were read during April and May before the Institution of Mechanical Engineers. Its application, as the fluid flywheel, to automobile drives has attracted to it the attention of a much wider public than the engineering profession.

Some misconception is prevalent regarding this method of transmission. While it is rightly understood that power is transmitted from one disc-the 'driver' or 'impeller'-to another quite unconnected disc-the 'runner'-by the action of the oil which is kept in circulation, it is assumed by many that the oil is enabled to do this by acquiring some quality of lateral resistance due to an extraordinary degree either of shear resistance or of viscosity imparted to it by the circulatory velocity. In fact, how ever, the explanation is much simpler. 'The 'impeller' disc acts on the oil as a centrifugal pump imparting kinetic energy to it, and discharges it into the 'runner' dise, which operates as a turbine and receives energy from the liquid. Its discharge goes back to the impeller for the next cycle of energy transfer.

In his paper "Recent Developments in Hydraulic Couplings" (Proc. Inst. Mech. Eng., April 26) Mr. Harold Sinclair explains the fundamental differences between the two systems of hydraulic transmission-the displacement or hydro-static system and the turbo or hydro-kinetic system, to which latter these couplings and converters belong -and the main advantages of the turbo system. Following a brief historical survey from the pre-War speed trans. formers originated by Dr. Föttinger for marine turbine propulsion, he outlines the elements of the theory on which this type is based. Proceeding mainly in a descriptive and explanatory vein, the author devotes the bulk of his paper to the development of the Vulcan-Sinclair Coupling. This is a modific tion of the Vulcan marine type to meet the conditions of industrial and automotive service, and particulars are given of its application in three distinct forms : (1) the scoop type for constant speed motors driving variable speed machines, (2) the traction type, including the fluid flywheel, for variable speed engines and motors, and (3) the ring valve traction type for both constant and variable speed engines.

In "Voith Turbo Transmissions" (Proc. Inst. Mech. Eng., May 3) Dr.-Ing. Wilhelm Hahn discusses the application of torque converters and hydraulic couplings. The former, having in addition to the two discs - the 'impeller' and the 'runner'-a stationary guide ring, is enabled to step up the value of the torque and so is capable of overcoming a high starting resistance. After examining theoretically the relationship between power, torque and speed in a torque converter and considering the conditions for maximum efficiency, he suggests that, to attain as nearly as possible to the ideal torque curve, the torque converter be used for starting up and that, at the appropriate moment, a change-over be effected to the direct drive of a hydraulic coupling.

The necessity for this change-over and the duplication it involves arises from the practical difficulty of fitting the converter with variable blades on the stationary ring so that it is adaptable to all conditions. In "Progress in Design and Application of the Lysholm-Smith Torque Converter" (Proc. Inst. Mech. Eng., May 3), Messrs. Haworth and Lysholm discuss the theory of blade friction and the results of experiments. The main points to be provided for in design are set forth and the results of experiments showing the effects of various blade angles and wheel diameters are given, together with the results of several appliçations, including a 1,000 h.p. variable blade converter.

Taken together, the three papers give a very good picture of the present position in this practically new method of fluid transmission.

\section{The National Museum of Natural History, Paris}

$\mathrm{T}$ HE National Museum of Natural History, Paris, which was founded by Guy de la Brosse in May 1635 on the site of the Jardin des Plantes"Le Jardin du Roy"-by an edict of Louis XIII, celebrated its tercentenary in Paris during the last week of June. The celebrations commenced on June 21 with a reception of the delegates by the director and the professors of the Museum, but the most impressive part of the various ceremonies was the séance solennelle, which was held in a special marquee erected in the Jardin des Plantes on the afternoon of June 25. This ceremony was attended by about 570 French and foreign delegates, representing 35 academies, 71 universities, 117 scientific institutions and 110 scientific societies, and was honoured by the presence of M. Albert Lebrun, the President of the Republic. The Minister of Education, M. Mario Roustan, presided, and the delegates presented their addresses at the commencement of the séance.

Speeches were made by M. Paul Lemoine, director of the Muséum National d'Histoire Naturelle; by the Governor-General, M. Olivier (president of the Society of Friends of the Museum); by M. Alfred Lacroix (member of the Institute and professor at the Natural History Museum), speaking in the name of the Academies; by M. M. Caullery (member of the Institute and professor at the Sorbonne), in the name of the French delegates; and by Sir Arthur Hill (director of the Royal Botanic Gardens, Kew), 